\title{
On the halide hydration study: Development of first-principles halide ion-water interaction potential based on a polarizable model
}

\author{
Regla Ayala, José M. Martínez, Rafael R. Pappalardo, \\ and Enrique Sánchez Marcos ${ }^{\mathrm{a})}$ \\ Departamento de Química Física, Universidad de Sevilla 41012, Sevilla, Spain
}

(Received 27 May 2003; accepted 13 August 2003)

\begin{abstract}
The development of first-principles halide-water interaction potentials for fluoride and iodide anions is presented. The model adopted is the mobile charge densities in harmonic oscillator that allows for a flexible and polarizable character of the interacting particles. The set of points of the quantum mechanical potential energy surfaces are calculated up to the MP2 level. The nonadditive many-body contributions were included explicitly at the three-body terms. Structural and energetic properties of the $\left[X\left(\mathrm{H}_{2} \mathrm{O}\right)_{n}\right]^{-}$clusters $(n=1-6)$ are studied with the new interaction potentials developed. Halide aqueous solutions are also studied by means of Monte Carlo simulations. The agreement between experimental and our predicted estimations shows the good behavior of the proposed potentials. The developed potentials are able to properly describe both the microsolvation of clusters in gas phase and their hydration in aqueous solutions. The different nature of the interactions among $\mathrm{F}^{-}, \mathrm{Br}^{-}, \mathrm{I}^{-}$and water appears in the set of studied properties, thus giving a gradual change in the behavior along the group. (c) 2003 American Institute of Physics.
\end{abstract}

[DOI: $10.1063 / 1.1615764$ ]

\section{INTRODUCTION}

The structure and reactivity of solvated molecules and singly charged ions have been extensively investigated by both experiment and theory. ${ }^{1-9}$ Experimental determination of a detailed microscopic structure of solvation shells around ions is generally difficult, therefore, computer simulations could be of help providing crucial insight into the structure and dynamics of these solvation shells. Computer simulations have emerged as a powerful tool for investigating the microscopic properties of liquids and liquid solutions. ${ }^{10,11}$ The reliability of the results derived from numerical simulations depends critically on the potential model describing the interactions among the particles defining the system. Thus, the development of interaction potentials is currently a topic of increasing importance in both fundamental and applied research. ${ }^{12,13}$ Most of these studies have been focused on cation hydration, due to its important role in many chemical and biochemical processes. ${ }^{4}$ Anion hydration has been less studied, although its role even as counterions is needed to fulfill the picture of solvation. Halide anions are among the most common anions present in nature, and consequently halide anion-water are among the most extensively studied systems. ${ }^{1}$

The purpose of this work is to provide insight into the halide hydration taking into account the differences and similarities that appear as a function of the ion size, its polarizing and polarizable character and the strength of the halide-water interaction. In order to address some key points about halide hydration, such as the way that water-water structure is

\footnotetext{
a) Author to whom correspondence should be addressed. Electronic mail: sanchez@simulux.us.es
}

modified by the halide presence, we have developed firstprinciples halide ion-water interaction potentials using the mobile charge densities in harmonic oscillator model (MCDHO) developed by Ortega-Blake et al. ${ }^{14}$ This potential includes the polarizable and flexible character of the interacting particles. Stress has been put in the comparison between properties of the solvent in the first solvation shell and those for the bulk. The chloride anion has been removed from this study due to the great deal of work that has been carried out on this anion and because of its similarity with the bromide ion. Recently, we have reported the development of a firstprinciples bromide-water interaction potential based on the MCDHO model, ${ }^{15}$ concluding that a potential built on the basis of BSSE-correction of two-body interactions, inclusion of three-body contributions and polarizable character of the particles in combination with a MCDHO water-water potential is useful in studying $\left[\mathrm{Br}\left(\mathrm{H}_{2} \mathrm{O}\right)_{n}\right]^{-}$clusters in gas phase, as well as simulation of these clusters at $298 \mathrm{~K}$ and bromide aqueous solutions. The no inclusion of BSSE correction in the pairwise interactions implied an overestimation of both solvation enthalpy and the number of water molecules surrounding the bromide anion in its vicinity. An examination of the different contributions of the bromide ion-water interactions ${ }^{16}$ showed that three-body interactions are mainly responsible for the non-pairwise additive character of the interactions. What's more, it has been demonstrated that the inclusion of three-body effects is important for a more accurate description of the solvation structure. ${ }^{17,18}$ Four-body contributions were by far less significant and they implied a considerably larger computational effort. A validation of the methodology used is also shown in a recently XAS (x-ray absorption spectroscopy) study ${ }^{19}$ of the bromide hydration in 
which experimental spectra are fairly well reproduced. In this work, we present an extension of this methodology to the fluoride and iodide anions.

The structure of halide hydrates has long been a subject of controversy, ${ }^{20-26}$ regarding the internal or surface arrangement of the halide ion in the cluster. It is well established that the structure of water molecules in the vicinity of an ion is the result of a compromise between ion-water interactions and the cooperative forces binding the solvent. When anions are solvated by water molecules, the ionic hydrogen bonding disrupts to a given extent the network of the solvent molecules depending on the particular ion. In this sense, the fluoride ion acts disrupting the framework of water structure in its closer vicinity, whereas iodide does not induce this perturbation. This is one of the reasons why fluoride hydration structure is different from that of the other halides.

Fluoride hydration has been studied in great detail in literature. In this way, quantum-mechanical ${ }^{27-37}$ and $\mathrm{QM} / \mathrm{MM}^{25,38}$ calculations, as well as classical ${ }^{39-44}$ and $a b$ initio simulations, ${ }^{45}$ have been carried out. Nevertheless, polarizable fluoride ion-water interaction potentials just based on first-principles have not been developed yet. In a parallel way, the iodide hydration has been studied by both quantum $^{23,28,36,46-50}$ and statistical ${ }^{51-55}$ methods. Again, to our best knowledge, there is no ab initio iodide ion-water interaction potential. In this work, we develop first-principles halide ion-water interaction potentials and explore the fundamental reasons for the differences in halide hydration.

The remainder of the article is organized as follows: Section II outlines the computational method. The development of the fluoride- and iodide-water interaction potentials and their validation, as well as a comparison of the microhydration and hydration along the group, is carried out in Sec. III; finally, the concluding remarks are presented in Sec. IV.

\section{METHODOLOGY}

This section is split up into two parts: in the first one the development of the fluoride- and iodide-water interaction potentials is explained and, in the second part, the procedures to carry out minimizations of $\left[X\left(\mathrm{H}_{2} \mathrm{O}\right)_{n}\right]^{-}(X \equiv \mathrm{F}, \mathrm{I})$ clusters and Monte Carlo (MC) simulations conditions are presented.

\section{A. Development of fluoride- and iodide-water interaction potentials}

\section{Outline of the MCDHO model}

The development of fluoride- and iodide-water interaction potentials has been performed adopting a MCDHO-type model. This shell-model includes intramolecular flexibility and polarizable character in the description of the species that form the system to simulate. The water molecule is described by three positive charges located in the experimental gas-phase geometry of the molecule, $Z_{\mathrm{O}}$ and $Z_{\mathrm{H}}$ being the value of the positive charges for the oxygen and hydrogen atoms, respectively. A negative mobile charge, $q_{\mathrm{O}}=-Z_{\mathrm{O}}$ $-2 Z_{\mathrm{H}}$, attached to the oxygen atom by an harmonic oscillator is used to model the polarizability (see Fig. 1). The intramolecular flexibility of water molecules is included by means of a Morse potential for the $\mathrm{O}-\mathrm{H}$ bonds and a fourth degree polynomial for the $\mathrm{HOH}$ angle, combined both with

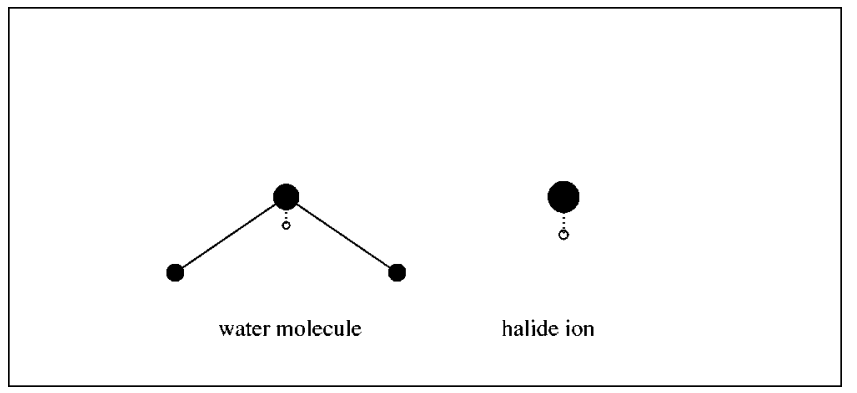

FIG. 1. Schematic representation of MCDHO model. Positive charges $Z_{\mathrm{O}}$, $Z_{\mathrm{H}}$ and $Z_{X^{-}}$are placed at the nuclei positions (bold sphere), and the mobile charges $q_{\mathrm{O}}$ and $q_{\mathrm{Br}^{-}}$are attached to the oxygen atom and the bromide atom by a harmonic oscillator potential (white sphere).

the electrostatic interaction among the charges, except the interaction between $Z_{\mathrm{O}}$ and $q_{\mathrm{O}}$ charges. In the case of the halide anions, the monoatomic ion is described by a positive charge, $Z_{X^{-}}$, and a negative mobile charge, $q_{X^{-}}$, with a total value, $q_{X^{-}}=-Z_{X^{-}}-1$, attached to it (see Fig. 1). The intraatomic energy is defined by $U_{X^{-}}=\frac{1}{2} k r^{2}$, where $r$ is the distance between the core and its associated mobile charge.

Water-water and bromide ion-water MCDHO-type interaction potentials have already been published in Refs. 14 and 15 , respectively. The fluoride- and iodide-water interaction potentials have been built by means of fitting a set of 14 parameters for each one on the basis of the following intermolecular terms:

(1) a classical 12-6-1 potential between the negative mobile charges $q_{\mathrm{O}}$ and $q_{X^{-}}, r$ being the distance between them, and $A$ and $B$ the Lennard-Jones parameters,

$$
U\left(q_{\mathrm{O}}, q_{X^{-}}\right)=\left(\frac{A_{X-\mathrm{O}}}{r}\right)^{12}-\left(\frac{B_{X-\mathrm{O}}}{r}\right)^{6}+\frac{q_{\mathrm{O}} q_{X^{-}}}{r}
$$

(2) an electrostatic interaction between $q_{\mathrm{O}}$ and $Z_{X^{-}}, r^{\prime}$ being the distance between the $q_{\mathrm{O}}$ and the nucleus of halide ion,

$$
U\left(q_{\mathrm{O}}, Z_{X^{-}}\right)=\frac{q_{\mathrm{O}} Z_{X^{-}}}{r^{\prime}}\left[1-\left(\frac{r^{\prime}}{\lambda_{\mathrm{O}}^{\prime}}+1\right) \exp \left(-2 \frac{r^{\prime}}{\lambda_{\mathrm{O}}^{\prime}}\right)\right],
$$

where $\lambda_{\mathrm{O}}^{\prime}$ corresponds to the intermolecular screening and it is responsible for the density character of the mobile charge;

(3) an electrostatic interaction between $q_{X^{-}}$and each of the charges on the nuclei of the water molecule $Z_{i}$ ( $i$ $\equiv \mathrm{O}, \mathrm{H})$ :

$$
U\left(Z_{i}, q_{X^{-}}\right)=\frac{Z_{i} q_{X^{-}}}{r_{i}}\left[1-\left(\frac{r_{i}}{\lambda_{X^{-}}^{\prime}}+1\right) \exp \left(-2 \frac{r_{i}}{\lambda_{X^{-}}^{\prime}}\right)\right],
$$

where $r_{i}$ is the distance between $q_{X^{-}}$and $Z_{i}$, and the $\lambda_{X^{-}}^{\prime}$ notation has been maintained for intermolecular interactions; and

(4) an interaction potential between the halide nucleus and each of the nuclei of the water molecule, which includes the electrostatic repulsion of their respective point-charges, and has two additional terms: 


$$
U\left(Z_{i}, Z_{X^{-}}\right)=\frac{C_{X-i}}{R_{i}^{s_{X-i}}}-\frac{D_{X-i}}{R_{i}^{p_{X-i}}}+\frac{Z_{i} Z_{X^{-}}}{R_{i}},
$$

where $C_{X-\mathrm{O}}, C_{X-\mathrm{H}}, D_{X-\mathrm{O}}, D_{X-\mathrm{H}}, s_{X-\mathrm{O}}, s_{X-\mathrm{H}}, p_{X-\mathrm{O}}$, $p_{X-\mathrm{H}}$, are adjustable parameters, and $R_{i}$ is the distance from the halide nucleus to the $i$-th nucleus of the water molecule.

\section{Exploration of the fluoride- and iodide-water potential energy surfaces}

The first step to develop a first-principles interaction potential is carrying out the exploration of the potential energy surfaces (PES) of the system. Dimers, $\left[X\left(\mathrm{H}_{2} \mathrm{O}\right)\right]^{-}$, and trimers, $\left[X\left(\mathrm{H}_{2} \mathrm{O}\right)_{2}\right]^{-}$, were considered in the case of the fluoride- and iodide-water systems. Water molecules were described by the aug-cc-pVTZ basis set in the dimers, ${ }^{56-58}$ whereas the aug-cc-pVDZ ${ }^{57-59}$ basis set was used for the trimers. The use of the aug-cc-pVTZ and aug-cc-pVDZ basis set is reasonable ${ }^{60-62}$ for the study of clusters with more than one water molecule which retain an important degree of hydrogen bonding. The fluoride ion was described with the aug-cc-pVTZ basis set, ${ }^{56,57}$ in both dimers and trimers. An effective core pseudopotential (ECP) was used to describe the core electrons in the description of the iodide ion, namely, the SDB-ECP, ${ }^{63}$ while the aug-cc-pVTZ basis sets augmented with polarization functions ${ }^{64}$ were used for the valence electrons. Previous studies ${ }^{33,65,66}$ have emphasized the need for taking into account basis sets containing diffuse functions when hydrogen bond plays a role in the bonding.

The interaction energy of the dimers were obtained with Møller-Plesset second-order perturbation theory (MP2), whereas the nonadditivities of three-body terms where computed at the SCF level. The basis set superposition error (BSSE) was corrected by the counterpoise method $^{67}$ in the case of the dimers. The choice of this computational strategy was guided by our earlier work on the bromide hydration, ${ }^{15}$ in which the description of pairwise interactions at the MP2 level BSSE-corrected and the inclusion of three-body terms at the SCF level were suitable to develop an appropriate first-principles bromide ion-water interaction potential. What's more, the corresponding bromide ion-water interaction potential, labeled as POT_2 in our previous work, ${ }^{15}$ was able to adequately reproduce four-body terms even though they were not included in its development.

There were 526 dimers and 123 trimers considered in the development of the fluoride-water interaction potential, which will be named hereafter POT_F. Dimers were obtained by scanning the $\mathrm{F}-\mathrm{O}$ distance (from 1.5 to $6.0 \AA$ ), the $\angle \mathrm{FHO}$ angle (from $180^{\circ}$ to $50^{\circ}$ ) and the $\angle \mathrm{FHOH}$ dihedral angle (from $0^{\circ}$ to $270^{\circ}$ ). Ninety-five of the dimers considered presented a water molecule geometry different from the experimental gas-phase one (the reference geometry used in the MCDHO water model), i.e., the structure of water molecules were optimized in those points. With regard to the nonadditivities, the geometries of the water molecules were not constrained to the experimental one. The geometries of the trimers were taken during the optimization procedure of $\left[\mathrm{F}\left(\mathrm{H}_{2} \mathrm{O}\right)_{n}\right]^{-}$clusters $(n=2-6)$. To test if inclusion of the three-body contributions is able to account for the reproduc-
TABLE I. POT_F and POT_I parameters in a. u. The standard deviations $\sigma$ are in $\mathrm{kcal} / \mathrm{mol}$ and show the degree of confidence of the fit. The parameters $Z_{\mathrm{O}}, q_{\mathrm{O}}$ and $\lambda_{\mathrm{O}}^{\prime}$ used in Eqs. (1)-(4) were obtained in the development of the MCDHO water model (Ref. 14) and have a value of $2.6,-3.9$, and 0.55505009 , respectively.

\begin{tabular}{ccc}
\hline \hline Parameters & POT_F & POT_I \\
\hline$Z_{X}$ & 0.78 & 12.017 \\
$q_{X}$ & -1.78 & -13.017 \\
$k$ & 0.48306209 & 4.4998256 \\
$A_{X-\mathrm{O}}$ & 2.6700817 & -3.832845 \\
$B_{X-\mathrm{O}}$ & 1.89112218 & -2.650078 \\
$\lambda_{X^{-}}^{\prime}$ & 0.60608410 & 0.66716262 \\
$C_{X-\mathrm{O}}$ & 357.9775 & 277.96127 \\
$s_{X-\mathrm{O}}$ & 5.3876496 & 5.5650850 \\
$D_{X-\mathrm{O}}$ & -257.79246 & -156.01907 \\
$p_{X-\mathrm{O}}$ & 5.1687341 & 4.9638329 \\
$C_{X-\mathrm{H}}$ & 19.124510 & 34.117550 \\
$s_{X-\mathrm{H}}$ & 7.7427334 & 17.218706 \\
$D_{X-\mathrm{H}}$ & 38.481319 & \\
$p_{X-\mathrm{H}}$ & 9.1069647 & \\
& Standard deviations $\sigma$ & \\
\hline $\mathrm{F}^{-}$ & & 0.649260 \\
$\mathrm{I}^{-}$ & & 0.2288 \\
\hline
\end{tabular}

tion of the four-body ones, 103 tetramers, $\left[\mathrm{F}\left(\mathrm{H}_{2} \mathrm{O}\right)_{3}\right]^{-}$, were considered. The computational level of the tetramers was the same as that used for the trimers.

The iodide-water interaction potential, labeled as POT_I, was developed taking into consideration 545 dimers and 67 trimers. Again, dimers structures were obtained by scanning the $\mathrm{I}-\mathrm{O}$ distance (from 2.0 to $6.5 \AA$ ), the $\angle \mathrm{IHO}$ angle (from $180^{\circ}$ to $50^{\circ}$ ) and the $\angle \mathrm{IHOH}$ dihedral angle (from $0^{\circ}$ to $270^{\circ}$ ). All the water molecules in the dimers but one, that corresponding to the $\left[\mathrm{I}\left(\mathrm{H}_{2} \mathrm{O}\right)\right]^{-}$global minimum, were rigid dimers, in the sense that the experimental gasphase geometry was kept fixed. This approximation is supported by the small change between the optimized isolated water molecule geometry at the level of computation used and the water molecule geometry at the global minimum of $\left[\mathrm{I}\left(\mathrm{H}_{2} \mathrm{O}\right)\right]^{-}$. The geometries of the trimers were selected in a similar way of the fluoride case.

All the calculations were carried out with the GAUSSIAN 98 program package. ${ }^{68}$

\section{Fitting procedure}

The interaction energy derived from the PESs of the fluoride- and iodide-water clusters were fitted to Eqs. (1)-(4) by means of a least-square fitting. Table I shows the set of parameters of POT_F and POT_I and the goodness of the fit. Validation of the potentials has been carried out by comparing the results of clusters minimizations and MC simulations with the available experimental and theoretical data.

\section{B. Minimizations procedure and Monte Carlo simulations conditions}

Numerical minimizations of the halide clusters and MC Metropolis simulations of the halide ion in water were carried out using the MCHANG program developed by Cuernavaca group. ${ }^{69}$ 
TABLE II. Details of the systems considered in the Monte Carlo simulations $\left(\mathrm{M} \equiv 10^{6}\right.$ and $\left.G \equiv 10^{9}\right)$.

\begin{tabular}{cccccc}
\hline \hline System & $\begin{array}{c}\text { No. of } \\
\text { ions }\end{array}$ & $\begin{array}{c}\text { No. of water } \\
\text { molecules }\end{array}$ & L $(\AA)$ & $\begin{array}{c}\text { No. of } \\
\text { equilibration } \\
\text { steps }\end{array}$ & $\begin{array}{c}\text { No. of run } \\
\text { steps }\end{array}$ \\
\hline & & & $\mathrm{F}^{-}$ & & \\
$\mathrm{A}$ & 1 & 120 & 15.3668 & $300 \mathrm{M}$ & $1 \mathrm{G}$ \\
$\mathrm{B}$ & 1 & 215 & 18.6399 & $500 \mathrm{M}$ & $1 \mathrm{G}$ \\
$\mathrm{C}$ & 1 & 511 & 24.8520 & $500 \mathrm{M}$ & $1 \mathrm{G}$ \\
& & & $\mathrm{Br}^{-}$ & & \\
$\mathrm{A}$ & 1 & 116 & 15.3406 & $300 \mathrm{M}$ & $800 \mathrm{M}$ \\
$\mathrm{B}$ & 1 & 211 & 18.6221 & $500 \mathrm{M}$ & $3.5 \mathrm{G}$ \\
$\mathrm{C}$ & 1 & 507 & 24.8420 & $500 \mathrm{M}$ & $1 \mathrm{G}$ \\
& & & $\mathrm{I}^{-}$ & & \\
$\mathrm{A}$ & 1 & 115 & 15.4088 & $300 \mathrm{M}$ & $1 \mathrm{G}$ \\
$\mathrm{B}$ & 1 & 210 & 18.6684 & $500 \mathrm{M}$ & $1 \mathrm{G}$ \\
$\mathrm{C}$ & 1 & 506 & 24.8680 & $500 \mathrm{M}$ & $1 \mathrm{G}$ \\
\hline \hline
\end{tabular}

Numerical minimizations of $\left[X\left(\mathrm{H}_{2} \mathrm{O}\right)_{n}\right]^{-}(X \equiv \mathrm{F}, \mathrm{I}$ and $n=1-6)$ clusters were performed at $0 \mathrm{~K}$. These clusters were minimized in vacuum, with no periodic boundary conditions. Kim et al..$^{27,28,36}$ among others, ${ }^{15,16,25,32,38,45,70,71}$ show the great number of possible minima that are accessible in halide ion-water PESs. The interplay between ion-water and water-water interactions results in the existence of more than one structure exhibiting different hydrogen bonding network and similar energies. To ensure adequate sampling of the multidimensional PESs, minimizations initiated at different starting points were performed. On one hand, the $\left[\mathrm{Br}\left(\mathrm{H}_{2} \mathrm{O}\right)_{n}\right]^{-}$minima structures obtained in our previous works ${ }^{15,16}$ were chosen as initial guess. On the other hand, random geometries were taken as starting configurations.

To compare with experimental binding enthalpies of $\left[X\left(\mathrm{H}_{2} \mathrm{O}\right)_{n}\right]^{-}$clusters, $\Delta H_{\text {bind }}$, MC simulations in the canonical ensemble (NVT) at $300 \mathrm{~K}$ were performed, including later on the enthalpy correction. To this end, we have taken the approximation of the ideal gas behavior for the formation reaction of the ionic cluster, i.e., $\Delta(P V) \sim \Delta n R T$.

MC simulations (NVT) at $298.15 \mathrm{~K}$ were also performed. Periodic boundary conditions and a spherical cutoff radius of $R_{\text {cut }}=L / 2, L$ being the box length, were used. Box dimensions were chosen to keep the density equal to $0.997 \mathrm{~g} / \mathrm{cm}^{3}$ for the different system sizes considered. The Ewald Summation technique ${ }^{10}$ including the charged system term $^{72,73}$ was used to handle long-range coulombic interactions. The $\sim 40 \%$ of acceptance for the configurations generated was kept during the simulation. Details of the different simulation systems considered are contained in Table II. Long equilibration periods were performed because the inclusion of the polarizability and the intramolecular flexibility highly increases the number of degrees of freedom of the system, compared to rigid and nonpolarizable particles.

Previous to discussing the validation of the potentials, the capability of POT_F to reproduce four-body nonadditivities will be presented. Figure 2 illustrates the correlation between four-body contributions at SCF level and those derived from POT_F, indicating that a first-principles halide

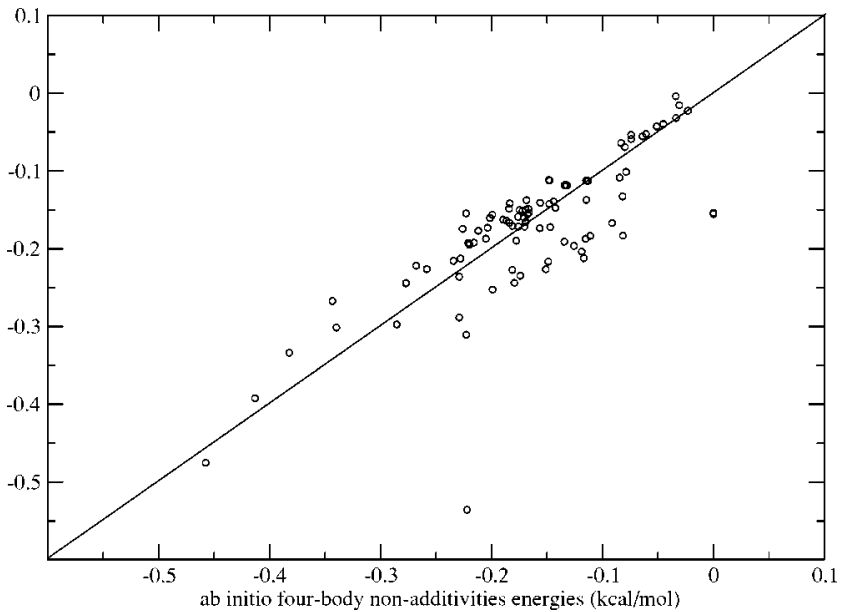

FIG. 2. Comparison of the ab initio and POT_F four-body contributions. Energies in $\mathrm{kcal} / \mathrm{mol}$.

ion-water interaction potential that includes three-body contributions is able to reproduce higher order terms.

\section{RESULTS AND DISCUSSION}

\section{A. Minimizations}

Numerical minimizations of cluster structures without constraints were carried out. Some representative results are shown in Fig. 3. Its analysis shows how water molecules in $\left[\mathrm{F}\left(\mathrm{H}_{2} \mathrm{O}\right)_{n}\right]^{-}$clusters interact with the ion quite individually. The $\mathrm{F}^{-}-\mathrm{H}_{2} \mathrm{O}$ interaction energy is stronger than that of the rest of the halide ions, being responsible for the decreasing of the hydrogen bonds among water molecules. For $n>3$, the presence of water molecules in the second hydration shell becomes important. $\mathrm{F}^{-}-\mathrm{H}_{2} \mathrm{O}$ interaction energy is about five times more stabilizing than the $\mathrm{H}_{2} \mathrm{O}-\mathrm{H}_{2} \mathrm{O}$ one, therefore, in a first step, it is difficult to understand this trend. The analysis of the dipole moment of water molecules clarifies the reason for the preference of water molecules in the second solvation shell against a direct interaction with the fluoride ion. The values of the water dipole moment $\left|\vec{\mu}_{\mathrm{H}_{2} \mathrm{O}}\right|$ and the $\mathrm{F}-\mathrm{O}$ distance of water molecules in some of the clusters considered are displayed in Table III. In cluster e, water molecules simultaneously interacting with the fluoride ion and the water molecule of the second solvation shell present a higher value of dipole moment module than those in cluster d $(2.8 \mathrm{D}$ versus $2.6 \mathrm{D})$, as well as shorter $\mathrm{F}-\mathrm{O}$ distances $(2.6$ $\AA$ versus $2.7 \AA$ ). These two effects are responsible for the great stability of the cluster e. On one hand, the $\mathrm{F}^{-}-\mathrm{H}_{2} \mathrm{O}$ interaction energy increases $\sim 4.5 \mathrm{kcal} / \mathrm{mol}$ for each water molecule interacting with a second solvation shell solvent molecule (1-2 and 2-3) in cluster e with respect to the $\mathrm{F}^{-}-\mathrm{H}_{2} \mathrm{O}$ interaction energy in cluster d. The $\mathrm{F}^{-}-\left(\mathrm{H}_{2} \mathrm{O}\right)_{2 \text { nd shell }}$ interaction energy is $14.6 \mathrm{kcal} / \mathrm{mol}$ smaller than the average of $\mathrm{F}^{-}-\mathrm{H}_{2} \mathrm{O}_{1 \text { st shell }}$ interaction energy in cluster d. On the other hand, the total $\mathrm{H}_{2} \mathrm{O}-\mathrm{H}_{2} \mathrm{O}$ interaction energy in cluster $\mathbf{e}$ is stabilized by $5.1 \mathrm{kcal} / \mathrm{mol}$ compared to cluster $\mathbf{d}$. This behavior appears in the different minima sampled; for example, all the water molecules in cluster $\mathbf{f}$ 


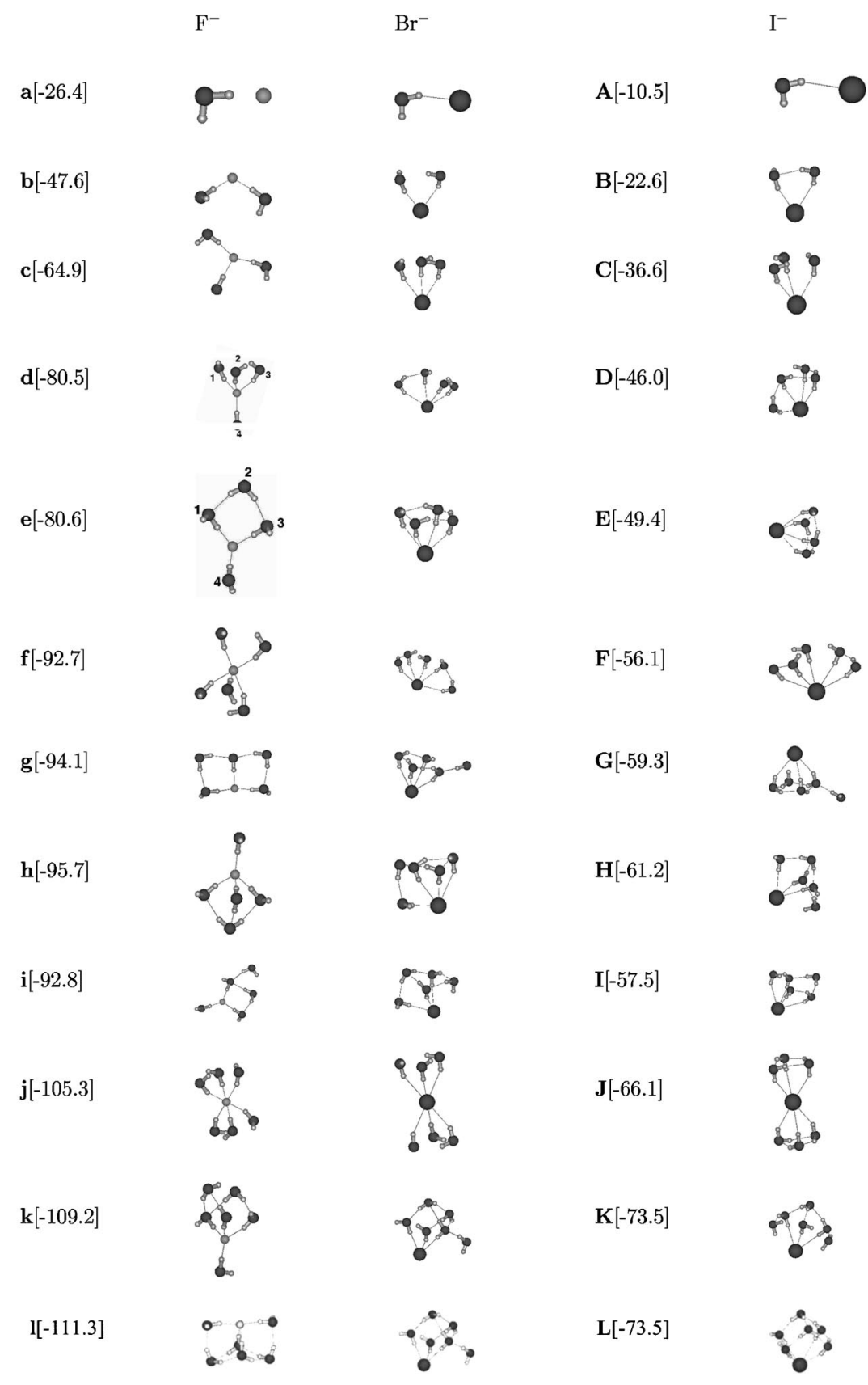

present a value of the dipole moment module in the range 2.5-2.6 D, while the two first-shell water molecules that interact with the hydrogen atoms of the water molecule in the second solvation shell in cluster $\mathbf{h}$ have a larger dipole moment $(2.7 \mathrm{D})$, as well as a shorter F-O distance. Likewise, there is an increasing of the dipole moment module (3.0 and $2.9 \mathrm{D})$ and a shortening in the ion-water distances for those solvent molecules interacting with the second solvation shell in cluster $\mathbf{k}$ comparing to those in cluster $\mathbf{j}(2.5 \mathrm{D})$. It is remarkable that dipole moments of water molecules depend strongly on their location in the cluster. The polarization of first-shell water molecules due to the fluoride ion increases the interaction between first and second shell water molecules to such extent that makes competitive the location of water molecules in the second shell. This fact has already been discussed by Vaughn et al $^{45}$ in a previous study of $\left[\mathrm{F}\left(\mathrm{H}_{2} \mathrm{O}\right)_{4}\right]^{-}$clusters.
FIG. 3. Optimized minimum energy geometries of $\left[\mathrm{F}\left(\mathrm{H}_{2} \mathrm{O}\right)_{n}\right]^{-}$and $\left[\mathrm{I}\left(\mathrm{H}_{2} \mathrm{O}\right)_{n}\right]^{-}$clusters $(n=1-6)$ obtained with POT_F and POT_I, respectively. Interaction energies appear between square brackets in kcal/ mol. $\left[\mathrm{F}\left(\mathrm{H}_{2} \mathrm{O}\right)_{n}\right]^{-}$and $\left[\mathrm{I}\left(\mathrm{H}_{2} \mathrm{O}\right)_{n}\right]^{-}$clusters are labeled in small letters and capital letters, respectively. $\left[\mathrm{Br}\left(\mathrm{H}_{2} \mathrm{O}\right)_{n}\right]^{-}$aggregates are taken from Ref. 15.

The extent of the halide ion-water interaction decreases as descending in the group, going from $\sim-26 \mathrm{kcal} / \mathrm{mol}$ for the fluoride ion to $\sim-10 \mathrm{kcal} / \mathrm{mol}$ for the iodide ion. The small iodide ion-water interaction energy leads to a more important competition between $\mathrm{H}_{2} \mathrm{O}-\mathrm{H}_{2} \mathrm{O}$ and $\mathrm{I}^{-}-\mathrm{H}_{2} \mathrm{O}$ interactions, enhancing the importance of $\mathrm{H}_{2} \mathrm{O}-\mathrm{H}_{2} \mathrm{O}$ structures, especially compared to the fluoride ion. Available quantum-mechanical studies about $\left.\left[\mathrm{I}_{(} \mathrm{H}_{2} \mathrm{O}\right)_{n}\right]^{-}$clusters show several similarities with respect to $\left[\mathrm{Br}\left(\mathrm{H}_{2} \mathrm{O}\right)_{n}\right]^{-}$ ones. $^{28,32,36}$ Some representatives results of the $\left[\mathrm{I}\left(\mathrm{H}_{2} \mathrm{O}\right)_{n}\right]^{-}$ $(n=1-6)$ minimizations are also displayed in Fig. 3 . It is worth pointing out the great importance of the $\mathrm{H}_{2} \mathrm{O}-\mathrm{H}_{2} \mathrm{O}$ interactions with respect to the rest of the halide ions. In this sense, $\mathrm{H}_{2} \mathrm{O}-\mathrm{H}_{2} \mathrm{O}$ interaction is $-5.92 \mathrm{kcal} / \mathrm{mol}$ in the $\left[\mathrm{Br}\left(\mathrm{H}_{2} \mathrm{O}\right)_{2}\right]^{-}$minimum and $-8.17 \mathrm{kcal} / \mathrm{mol}$ in the $\left[\mathrm{I}\left(\mathrm{H}_{2} \mathrm{O}\right)_{2}\right]^{-}$one (Fig. 3 B). Likewise, $\mathrm{H}_{2} \mathrm{O}-\mathrm{H}_{2} \mathrm{O}$ contributions to the total interaction energy in $\left[\mathrm{Br}\left(\mathrm{H}_{2} \mathrm{O}\right)_{4}\right]^{-}$and 
TABLE III. Variation of the dipole moment of the water molecules in the $\left[\mathrm{F}\left(\mathrm{H}_{2} \mathrm{O}\right)_{n}\right]^{-}$clusters.

\begin{tabular}{cccccc}
\hline \hline Structures & $\begin{array}{c}\text { F-O distance } \\
(\AA)\end{array}$ & $\begin{array}{c}\left|\vec{\mu}_{\mathrm{H}_{2} \mathrm{O}}\right| \\
(\mathrm{D})\end{array}$ & Structures & $\begin{array}{c}\mathrm{F}-\mathrm{O} \text { distance } \\
(\AA)\end{array}$ & $\begin{array}{c}\left|\vec{\mu}_{\mathrm{H}_{2} \mathrm{O}}\right| \\
(\mathrm{D})\end{array}$ \\
\hline $\mathbf{a}$ & 2.49 & 3.09 & $\mathbf{b}$ & 2.55 & 2.87 \\
& & & & 2.55 & 2.87 \\
& 2.62 & 2.61 & & 2.59 & 2.81 \\
$\mathbf{d}$ & 2.68 & 2.67 & $\mathbf{e}$ & 2.59 & 2.81 \\
& 2.68 & 2.65 & & 2.60 & 2.61 \\
& 2.69 & 2.66 & & 4.02 & 2.58 \\
& 2.68 & 2.51 & & 2.62 & 2.73 \\
& 2.72 & 2.61 & & 2.62 & 2.73 \\
$\mathbf{f}$ & 2.75 & 2.60 & $\mathbf{h}$ & 2.64 & 2.56 \\
& 2.76 & 2.55 & & 2.77 & 2.57 \\
& 2.82 & 2.56 & & 3.73 & 2.53 \\
& 2.80 & 2.53 & & & \\
& 2.80 & 2.53 & & 2.55 & 3.01 \\
& 2.80 & 2.53 & $\mathbf{k}$ & 2.64 & 2.55 \\
$\mathbf{j}$ & 2.80 & 2.53 & & 2.80 & 2.89 \\
& 2.80 & 2.53 & & 4.03 & 2.54 \\
& 2.80 & 2.53 & & 4.03 & 2.57 \\
& & & &
\end{tabular}

$\left[\mathrm{I}\left(\mathrm{H}_{2} \mathrm{O}\right)_{4}\right]^{-}$global minima (Fig. 3 E) are -13.4 and $-17.6 \mathrm{kcal} / \mathrm{mol}$, respectively. This behavior is repeated along all minima investigated.

The arrangement of water molecules around halide ions reveals important differences between the fluoride and the bromide and iodide ions. The bromide and iodide ions cause a small perturbation in the framework of water molecules structure, while the fluoride ion is able to disrupt that structure. In fact, the patterns that can be identified in pure water can also be recognized in the bromide and iodide hydrates, the effect being more noticeable in the latter case. The size of these two anions allows ion-water interactions without substantial increasing of water-water distance which would destabilize the system. From $n \geqslant 2, \mathrm{Br}^{-}$- and $\mathrm{I}^{-}$-water clusters are mainly superficials; by being on the surface the anion does not alter the hydrogen bonded network between the water molecules lowering the total energy of the cluster. $\left[\mathrm{F}\left(\mathrm{H}_{2} \mathrm{O}\right)_{n}\right]^{-}$clusters are characterized because water molecules form a chain in which end waters interact with the ion whereas the central water does not (e.g., e, g, h, in Fig. 3). Contrary, water molecules interact simultaneously among them and with halide ion in $\left[\mathrm{Br}\left(\mathrm{H}_{2} \mathrm{O}\right)_{n}\right]^{-}$and $\left[\mathrm{I}\left(\mathrm{H}_{2} \mathrm{O}\right)_{n}\right]^{-}$ clusters (e.g., D, E, F, in Fig. 3).

The analysis of Fig. 3 indicates a greater importance of the interior structures in the case of the fluoride aggregates with respect to the bromide and iodide ones. Besides, the energy differences between interior and surface clusters increase as descending in the group (see for example clusters $\mathbf{k}$ and $\mathbf{l}$ for $\mathrm{F}^{-}$ion and $\mathbf{J}$ and $\mathbf{K}$ for $\mathrm{I}^{-}$ion).

Previous studies have shown $25,27,28,36,45,74$ that the gap between surface and interior states decreases when zero point vibrational effects and thermal corrections are taken into consideration. These terms could reverse the stability order in the case of the fluoride ion.

The comparison of the interaction energies of the minima obtained with POT_F and POT_I and those computed from $a b$ initio calculations ${ }^{28,32,36}$ is shown in Table IV. There is a good correlation especially when large basis sets are used at the MP2 level. It is significant to mention that not only are the values very similar to the $a b$ initio results but also the stability order derived from the developed potentials holds up. The only discrepancy appears for $n=4$ in the case of the fluoride ion; nevertheless, previous results ${ }^{32,36,38}$ about the relative stability of these two structures ( $\mathbf{d}$ and $\mathbf{e}$ ) and the small differences between them make this particular case less important.

The comparison of the experimental enthalpies of binding for halide ion- $\left(\mathrm{H}_{2} \mathrm{O}\right)_{n}$ clusters at $300 \mathrm{~K}, \Delta H_{\text {bind }}$, with data derived from POT_F and POT_I is shown in Table V. Estimations given by other interaction potentials are also included in the table. It is noteworthy that classical simulations cannot be effectively parametrized to describe quantum behaviors, such as tunneling effects. Thus, the experimental

TABLE IV. Comparison between results calculated using the interaction potentials developed and ab initio methods. Interaction energies in $\mathrm{kcal} / \mathrm{mol}$.

\begin{tabular}{ccccccc}
\hline \hline Structure $^{\mathrm{a}}$ & $n$ & POT_F & ab initio & Structure $^{\mathrm{a}}$ & POT_I & ab initio \\
\hline $\mathbf{a}$ & 1 & -26.4 & $-26.1 \pm 0.6,{ }^{\mathrm{b}}-25.9 \pm 1.5^{\mathrm{c}}$ & $\mathbf{A}$ & -10.5 & $-10.6 \pm 0.6^{\mathrm{c}}$ \\
$\mathbf{b}$ & 2 & -47.6 & $-47.3 \pm 1.0,^{\mathrm{b}}-46.5 \pm 2.6^{\mathrm{c}}$ & $\mathbf{B}$ & -22.6 & $-22.3 \pm 1.5^{\mathrm{c}}$ \\
$\mathbf{c}$ & 3 & -65.3 & $-64.9 \pm 1.4,^{\mathrm{b}}-63.7 \pm 3.7^{\mathrm{c}}$ & $\mathbf{C}$ & -36.6 & $-35.4 \pm 2.9^{\mathrm{c}}$ \\
$\mathbf{d}$ & 4 & -80.5 & $-79.7 \pm 1.7,,^{\mathrm{b}}-78.9 \pm 4.9^{\mathrm{c}}$ & $\mathbf{D}$ & -46.0 & $-44.6 \pm 3.73^{\mathrm{c}}$ \\
$\mathbf{e}$ & 4 & -80.6 & $-78.3 \pm 5.3^{\mathrm{c}}$ & $\mathbf{E}$ & -49.4 & $-48.0 \pm 4.3^{\mathrm{c}}$ \\
$\mathbf{f}$ & 5 & -92.7 & $-90.2^{\mathrm{d}}$ & $\mathbf{F}$ & -59.3 & $-54.59^{\mathrm{d}}$ \\
$\mathbf{g}$ & 5 & -94.1 & $-90.6^{\mathrm{d}}$ & $\mathbf{G}$ & -61.2 & $-56.26^{\mathrm{d}}$ \\
$\mathbf{i}$ & 6 & -105.3 & $-100.6^{\mathrm{d}}$ & $\mathbf{I}$ & -66.1 & $-60.8^{\mathrm{d}}$ \\
$\mathbf{I}$ & 6 & -109.2 & $-106.2^{\mathrm{d}}$ & $\mathbf{L}$ & -73.5 & $-67.7^{\mathrm{d}}$ \\
$\mathbf{m}$ & 6 & -111.3 & $-107.4^{\mathrm{d}}$ & $\mathbf{M}$ & -73.5 & $-67.7^{\mathrm{d}}$ \\
\hline \hline
\end{tabular}

${ }^{\mathrm{a}}$ Minimum structures considered are displayed in Fig. 3.

${ }^{\mathrm{b}}$ Interaction energies at MP2/TZ(2df,pd) ++ level, reported in Ref. 28. Interaction energy is computed as follows: $\Delta E_{e}=\left(\Delta E_{e}^{N}+\Delta E_{e}^{B}\right) / 2 \pm \mathrm{BSSE} / 2$, where $\Delta E_{e}^{N}$ and $\Delta E_{e}^{B}$ are the interaction energies without and with BSSE correction.

'Interaction energies at MP2/6-311+ $+\mathrm{G}^{* *}$ level, reported in Ref. 28. Interaction energy is computed as in the previous note.

dinteraction energies at BLYP/6-311++ $\mathrm{G}^{* *}$ level, reported in Ref. 36. Interaction energies included 50\% of BSSE correction. 
TABLE V. Comparison of the experimental binding enthalpies for the formation reaction of the ionic cluster at $300 \mathrm{~K}$ with the estimations derived from POT_F and POT_I. Energies in kcal/mol.

\begin{tabular}{|c|c|c|c|c|c|c|}
\hline$n$ & POT_F & Other potentials & Exp. & POT_I & Other potentials & Exp. \\
\hline 1 & -24.7 & $-26.5^{\mathrm{a}}$ & $-23.3^{\mathrm{c}}$ & -9.5 & $-10.2^{\mathrm{e}}-10.2^{\mathrm{f}}$ & $-10.2^{\mathrm{c}}-10.2^{\mathrm{d}}$ \\
\hline 2 & -44.2 & $-48.1,{ }^{\mathrm{a}}-45.5^{\mathrm{b}}$ & $-39.9,^{\mathrm{c}}-42.5^{\mathrm{d}}$ & -19.3 & $-19.8^{\mathrm{c}}-20.0^{\mathrm{f}}$ & $-19.8^{c}-20.0^{d}$ \\
\hline 3 & -60.2 & $-66.4,^{\mathrm{a}}-61.8^{\mathrm{b}}$ & $-53.6^{\mathrm{c}}-57.8^{\mathrm{d}}$ & -30.0 & $-29.5,^{c}-29.6^{f}$ & $-29.0,{ }^{\mathrm{c}}-29.4^{\mathrm{d}}$ \\
\hline 4 & -72.1 & $-80.2,^{\mathrm{a}}-73.6^{\mathrm{b}}$ & $-67.1,^{c}-71.7^{d}$ & -40.6 & $-39.0,^{\mathrm{c}}-39.1^{\mathrm{f}}$ & $-38.2^{c}-38.5^{d}$ \\
\hline 5 & -83.0 & $-91.1,^{\mathrm{a}}-86.2^{\mathrm{b}}$ & $-80.3,^{\mathrm{c}}-84.0^{\mathrm{d}}$ & -51.5 & $-48.1,^{\mathrm{c}}-48.5^{\mathrm{c}}$ & $-47.2^{\mathrm{d}}$ \\
\hline 6 & -92.8 & $-101.6,^{\mathrm{a}}-96.4^{\mathrm{b}}$ & $-94.6^{c}$ & -61.4 & & \\
\hline 7 & -102.2 & $-112.0,^{\mathrm{a}}-109.1^{\mathrm{b}}$ & $-105.3^{c}$ & & & \\
\hline 8 & -115.8 & $-120.7,^{\mathrm{a}}-118.7^{\mathrm{b}}$ & $-116.5^{\mathrm{c}}$ & & & \\
\hline 9 & -129.9 & $-134.3,^{\mathrm{a}}-128.5^{\mathrm{b}}$ & $-127.6^{c}$ & & & \\
\hline
\end{tabular}

${ }^{\mathrm{a}}$ Reference 40.

${ }^{\mathrm{b}}$ Reference 42.

${ }^{\mathrm{c}}$ Reference 6.
${ }^{\mathrm{d}}$ Reference 79

${ }^{\mathrm{e}}$ Reference 52.

${ }^{\mathrm{f}}$ Reference 53. findings can only be reproduced reasonably. The agreement found is acceptable considering that deviations are smaller than $5 \%$.

In the case of the fluoride ion, both quantum ${ }^{27-36}$ and statistical $^{25,38-45}$ calculations postulate the existence of minima where not all the water molecules directly interact with the halide ion. Nevertheless, Cabarcos et al. ${ }^{29}$ do not find evidences of $\mathrm{H}_{2} \mathrm{O}-\mathrm{H}_{2} \mathrm{O}$ hydrogen bonding through the study of $\mathrm{O}-\mathrm{H}$ stretching region in the experimental vibrational spectra of size-selected $\left[\mathrm{F}\left(\mathrm{H}_{2} \mathrm{O}\right)_{3-5}\right]^{-}$clusters at $\sim 300 \mathrm{~K}$. Among the experimental techniques, vibrational spectroscopy is an especially useful tool since a vibrational analysis may confirm or exclude the existence of particular structural fragment. It seems then interesting to study the effect of temperature on the structure of $\left[\mathrm{F}\left(\mathrm{H}_{2} \mathrm{O}\right)_{n}\right]^{-}$clusters. The analysis of $200 \mathrm{M}\left(M \equiv 10^{6}\right)$ configurations for $n$ $=3-4$ at $300 \mathrm{~K}$ showed the prevalence of structures which do not present water-water hydrogen bonds against those that do present them. However, in the case of $n=5$, the percentage of structures with hydrogen bonds is more significant. It may be stressed that there is not a rigid defined structure at this temperature, large geometry fluctuations and water exchanges being favored, so that one should not try to reduce the understanding of halide hydration in terms of local minima at $0 \mathrm{~K}$.

\section{B. Monte Carlo simulations}

In order to describe the thermodynamic and structural properties of the halide hydration and compare among them, numerical MC simulations under the conditions previously described were performed.

A summary of the thermodynamic and structural properties derived from numerical MC simulations containing the halide ions is given in Table VI.

\section{1. $X-O$ and $X-H$ RDFs}

The $\mathrm{F}-\mathrm{O}$ and $\mathrm{F}-\mathrm{H}$ RDFs, as well as their running integration numbers, are displayed in Fig. 4. The F-O RDF shows a first peak centered at $2.7 \AA$ which goes down to 0.16 and integrates to 5 oxygen atoms. The first peak of $\mathrm{F}-\mathrm{O}$ $\mathrm{RDF}$ is sharper than in the case of the bromide and iodide ions. In the same way, F-H RDF presents a first peak cen- tered at $1.65 \AA$ and also integrates to 5 hydrogen atoms, indicating that all the water molecules of the first solvation shell orient one of their hydrogen atoms toward the fluoride ion. In our previous work, ${ }^{15}$ the integration numbers of oxygen and hydrogen atoms around the bromide ion were 7 and 6 , respectively, which indicated an incomplete linearity of hydrogen bonding in the first hydration shell with regard to the ion.

The $\mathrm{I}-\mathrm{O}$ and $\mathrm{I}-\mathrm{H}$ RDFs and their running integration numbers are also displayed in Fig. 4. The $\mathrm{I}-\mathrm{O}$ and $\mathrm{I}-\mathrm{H}$ RDFs show a first peak centered at 3.64 and $2.71 \AA$, respectively. The first one integrates to $\sim 8$ oxygen atoms and the second one to $\sim 6$ hydrogen atoms.

The analysis of the set of $X-\mathrm{O}$ and $X-\mathrm{H}$ RDFs in Fig. 4 shows that the depletion beyond the first peak disappears as descending in the group. This complicates the quantification of the coordination numbers as a consequence of the increasing exchange between first and second solvation shells. Experimental evidences show this fact. ${ }^{1}$ Furthermore, the higher the atomic number is, the greater difference appears between the $X-\mathrm{O}$ and $X-\mathrm{H}$ coordination numbers (see Table VI). This behavior could lie on the orientation of the water molecules around the halide ion. Besides, the relative importance of the second and third peaks decreases with respect to

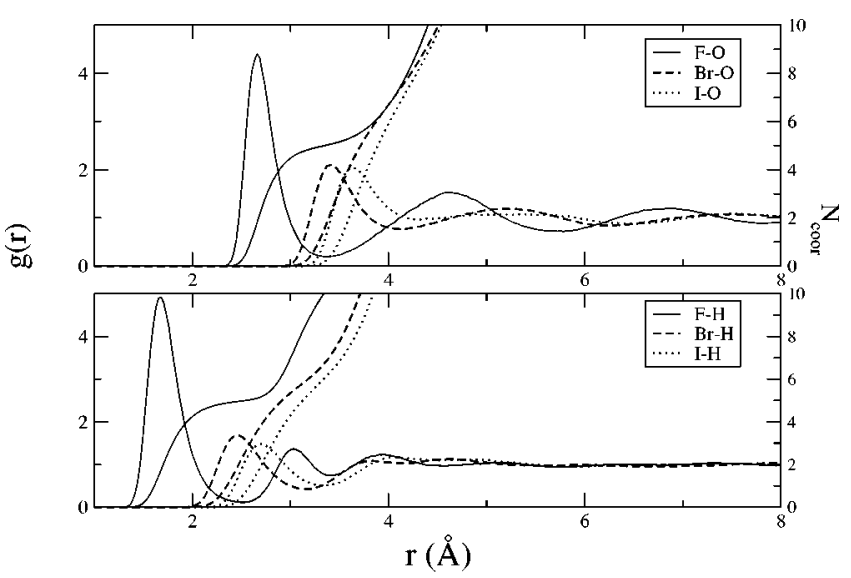

FIG. 4. $X-\mathrm{O}$ and $X-\mathrm{H}$ radial distribution functions and their running numbers from Monte Carlo simulations. 
TABLE VI. Summary of the structural and energetic properties derived from Monte Carlo simulations ( $\alpha$ in $\AA^{3}$ and energies in kcal/mol).

\begin{tabular}{|c|c|c|c|c|c|c|c|c|c|}
\hline Parameters & POT_F & $\begin{array}{c}\text { Other } \\
\text { potentials }\end{array}$ & Expt. & POT_Br ${ }^{\mathrm{a}}$ & $\begin{array}{c}\text { Other } \\
\text { potentials }\end{array}$ & Expt. & POT_I & $\begin{array}{c}\text { Other } \\
\text { potentials }\end{array}$ & Expt. \\
\hline$\alpha_{\mathrm{F}^{-}}$ & 0.97 & & $0.87^{\mathrm{b}}$ & 4.0 & & $4.85^{\mathrm{b}}$ & 5.8 & & $7.5^{\mathrm{b}}$ \\
\hline$\Delta H_{h y d}{ }^{\mathrm{c}}$ & $-134.5 \pm 8$ & & & $-78.5 \pm 3$ & & & $-74.2 \pm 4$ & & \\
\hline$\Delta H_{\text {hyd }}{ }^{\mathrm{d}}$ & $-132.0 \pm 5$ & $-115 \pm 4^{f}$ & $-124 . \pm 10^{\mathrm{g}}$ & $-80.8 \pm 5$ & & $-82.5 \pm 4$ & $-75.7 \pm 6$ & $-64.4 \pm 3,^{\mathrm{h}}-81.2 \pm 4^{\mathrm{i}}$ & $-71.4 \pm 10^{\mathrm{g}}$ \\
\hline$\Delta H_{h y d}{ }^{\mathrm{e}}$ & $-137.8 \pm 8$ & & & $-81.5 \pm 4$ & & & $-76.2 \pm 10$ & & \\
\hline $\begin{array}{c}g_{X-\mathrm{O}}(r) \\
\text { max. first peak }\end{array}$ & 2.65 & $2.7^{\mathrm{f}}$ & $2.62-2.69^{\mathrm{j}}$ & 3.43 & 3.37 & $3.30-3.43$ & 3.64 & $3.55,{ }^{\mathrm{h}} 3.60,{ }^{\mathrm{i}} 3.68^{\mathrm{k}}$ & $3.55-3.70^{\mathrm{j}}$ \\
\hline $\begin{array}{l}\mathrm{N}_{\text {coor }_{X-\mathrm{O}}} \\
\text { first shell }\end{array}$ & 5.1 & $6,{ }^{\mathrm{f}} 5.7^{1}$ & $4-6^{j}$ & 7.0 & $7.5^{\mathrm{m}}$ & $6-8^{\mathrm{j}}$ & 8.3 & $6.5,{ }^{\mathrm{h}} 7.3,{ }^{\mathrm{i}} 8.7^{\mathrm{l}}$ & $6-9^{j}$ \\
\hline $\begin{array}{c}g_{X-\mathrm{H}}(r) \\
\text { max. first peak }\end{array}$ & 1.7 & & & $2.50^{\mathrm{m}}$ & 2.32 & & 2.71 & $2.55,^{\mathrm{g}} 2.70,^{\mathrm{h}} 2.70^{\mathrm{l}}$ & \\
\hline $\begin{array}{l}\mathrm{N}_{\text {coor }_{X-\mathrm{H}}} \\
\text { first shell }\end{array}$ & 5 & & & 5.96 & $5.7^{\mathrm{m}}$ & & 6 & & \\
\hline
\end{tabular}

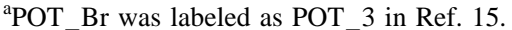

${ }^{\mathrm{b}}$ Reference 3 .

${ }^{\mathrm{c}} \mathrm{All}$ the properties refer to the system labeled in Table II as A.

${ }^{\mathrm{d}}$ All the properties refer to the system labeled in Table II as B.

${ }^{\mathrm{e}} \mathrm{All}$ the properties refer to the system labeled in Table II as C.

${ }^{\mathrm{f}}$ Reference 40.

${ }^{\mathrm{g}}$ Reference 2.

the first one as descending in the group, indicating a loss of structure in the second and third solvation shells.

\section{Distortion of water molecules}

The effects of the anion presence on the intramolecular geometry of the water molecules have been investigated. Statistically independent samples of $60 \mathrm{M}$ configurations were analyzed for systems containing 1 fluoride ion and 215 water molecules, 1 bromide anion and 211 water molecules, and 1 iodide ion and 210 water molecules. Along the different trajectories the following parameters were studied: the $\angle \mathrm{HOH}$ angle and the $\mathrm{O}-\mathrm{H}$ distance.

The distortion of the water molecule angle as a function of the $X-\mathrm{O}$ distance is shown in Fig. 5(a). The distribution of this value in the first solvation shell is displayed in Fig. 5(b). The analysis of both plots concludes that water molecules do not suffer important angular distortions in the vicinity of the anion. The halide effect on the water structure is more significant on the $\mathrm{O}-\mathrm{H}$ distance [Fig. 5(c)]. This distortion decreases when going from $\mathrm{F}^{-}$to $\mathrm{I}^{-}$, only being important in the first hydration shell.

It is worth stressing that water distortion is more important from an energetic point of view than from a structural one. The comparison between the energetic cost of water distortion in the $\left[\mathrm{F}\left(\mathrm{H}_{2} \mathrm{O}\right)\right]^{-}$and $\left[\mathrm{Li}\left(\mathrm{H}_{2} \mathrm{O}\right)\right]^{+}$global minimum structure is 5.17 versus $0.05 \mathrm{kcal} / \mathrm{mol}$. This fact could be surprising taking into account that the cation-water interaction is more important than the anion-water one $(-36.6$ versus $-26.4 \mathrm{kcal} / \mathrm{mol}){ }^{75}$ Nevertheless, cation-water interaction is mainly an ion-dipole one, whereas anion-water interaction is based on a strong hydrogen bonding. Thus, water distortion in the $\left[\mathrm{F}\left(\mathrm{H}_{2} \mathrm{O}\right)\right]^{-}$cluster implies a nonsymmetric lengthening of the $\mathrm{O}-\mathrm{H}$ distance which assumes a higher energy cost.
${ }^{\mathrm{h}}$ Reference 53.

${ }^{\mathrm{i}}$ Reference 52.

${ }^{\mathrm{j}}$ Reference 1.

${ }^{\mathrm{k}}$ Reference 80 .

${ }^{1}$ Reference 39.

${ }^{\mathrm{m}}$ Reference 76 .

\section{Orientational parameters}

The effect of the halide on the framework of water molecules in its vicinity has also been investigated by means of the analysis of the tilt angle, $\phi$, formed by the water dipole moment and the $X-\mathrm{O}$ vector, and the $\angle \mathrm{XHO}$ angle, $\gamma$ (Scheme 1):
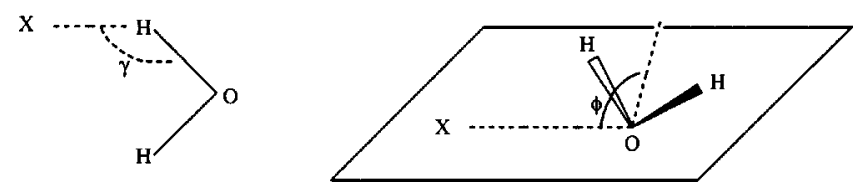

Figure 6(a) shows the variation of the $\phi$ and $\gamma$ angles as a function of the $X-\mathrm{O}$ distance. There is a decreasing of the $\gamma$ angle for the water molecules closer to the ion as descending in the group. This variation is caused by two different effects. On one hand, the linearity of the $X$-water hydrogen bonding decreases, as already observed for the dimers. On the other hand, the loss of orientation of water molecules in the first hydration shell from $\mathrm{F}^{-}$to $\mathrm{I}^{-}$causes a decreasing of the average value of the $\gamma$ angle. The analysis of the distribution of $\phi$ and $\gamma$ angles in the first hydration shell [Figs. 6(b) and 6(c), respectively] indicates an increasing of the dispersion of these values from $\mathrm{F}^{-}$to $\mathrm{I}^{-}$.

\section{Water dipole moment}

The use of a polarizable model allows the study of the variation of the water dipole moment in halide solutions. The distribution of the module of the dipole moment of water molecules, $\left|\vec{\mu}_{\mathrm{H}_{2} \mathrm{O}}\right|$, in the first hydration shell of the halide ion and one water molecule in pure water is shown in Fig. 7(a). The analysis of this plot indicates a decreasing of the magnitude as descending in the group. This decreasing is partly responsible for the different structures of fluoride- 

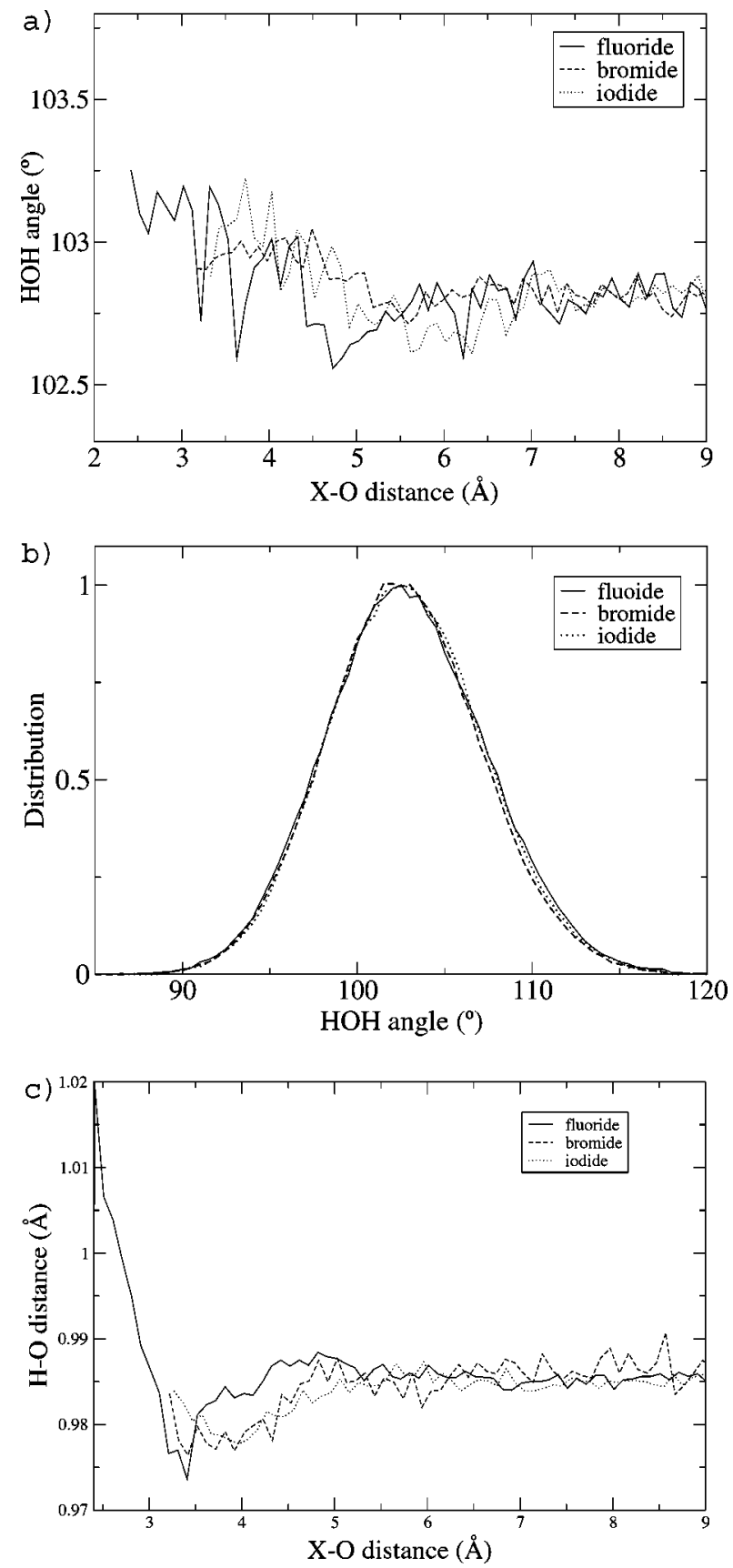

FIG. 5. Structural properties of water molecules obtained from MC simulations with POT_F, POT_Br and POT_I. (a) Average $\mathrm{HOH}$ angle as a function of the $X-\mathrm{O}$ distance. (b) Distribution of the angle in the first solvation shell is displayed. (c) Average $\mathrm{O}-\mathrm{H}$ distance nearer to the halide ion as a function of the $X-\mathrm{O}$ distance.

water clusters and the bromide and iodide-water ones. The same consequence is obtained when the variation of $\left|\vec{\mu}_{\mathrm{H}_{2} \mathrm{O}}\right|$ with the $X-\mathrm{O}$ distance is considered [Fig. 7(b)].

\section{Induced dipole moment and polarizability of halide ion}

The induced dipole moment for halides can also be computed because of the polarizable character of the anion in the model used. A value $\sim 0.2 \mathrm{D}$ is obtained for the fluoride ion. The values of this magnitude for the bromide and iodide ions a)

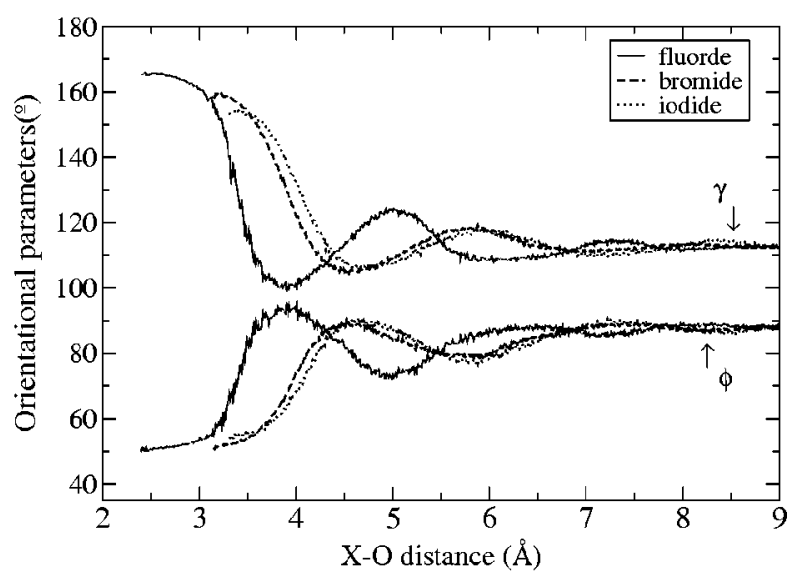

b)

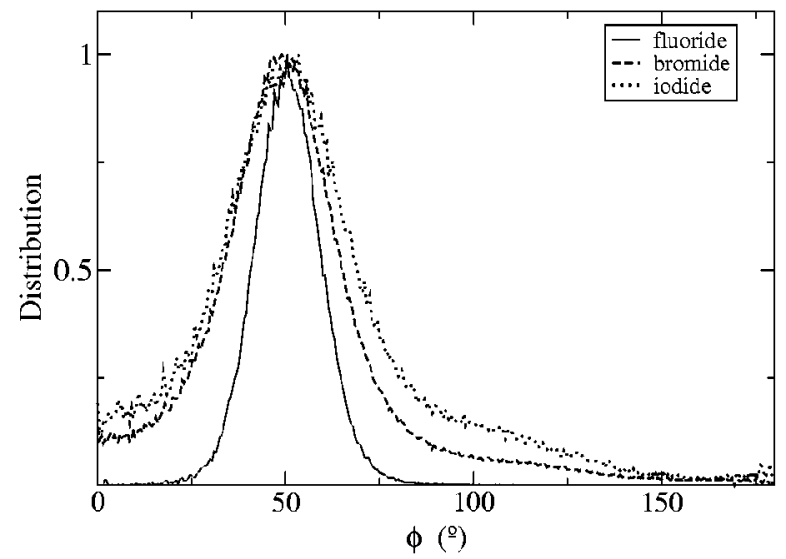

c)

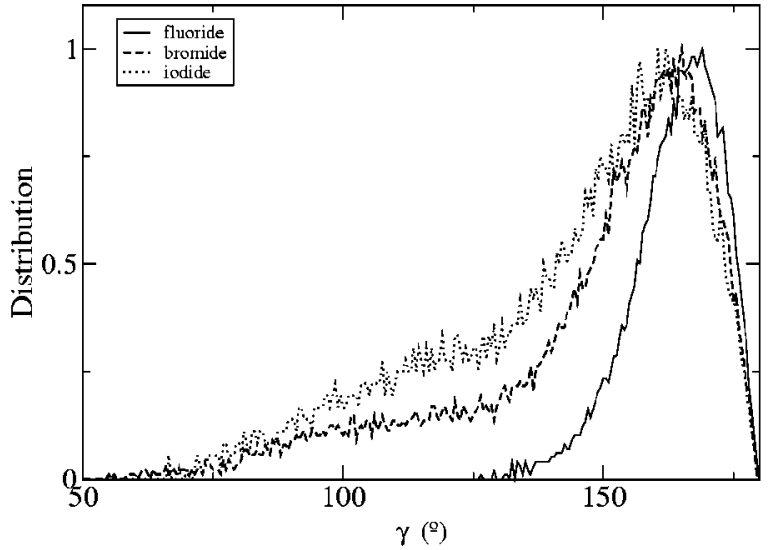

FIG. 6. Orientational parameters of water molecules with respect to the halide anion, as defined in Scheme 1: $\gamma$ is the $\angle \mathrm{XHO}$ angle, and $\phi$ is the angle between the dipole moment of a water molecule and the vector connecting the anion and the oxygen atom. (a) Average $\gamma$ and $\phi$ angles as functions of the $X-\mathrm{O}$ distance. (b) Distribution of the angle $\phi$ in the first solvation shell. (c) Distribution of the angle $\gamma$ in the first solvation shell.

are in the intervals $0.8-0.9$ and $1.2-1.5 \mathrm{D}$, respectively. The increasing of the $\left|\vec{\mu}_{X^{-}}\right|$with atomic number is a consequence of the polarizable character of the halide ions. In the case of bromide ion, Raugei and Klein ${ }^{76}$ get similar results for the value of $\left|\vec{\mu}_{\mathrm{Br}_{\text {ind }}^{-}}\right|$in an ab initio simulation study. On the other hand, Tuñon et al. ${ }^{77}$ obtain a much smaller dipole moment $(0.21 \mathrm{D})$ in a $\mathrm{QM} / \mathrm{MM}$ study of bromide aqueous solutions. Raugei and Klein ${ }^{76}$ explain the discrepancy with $\mathrm{QM} / \mathrm{MM}$ results on the basis of the nonpolarizable water 

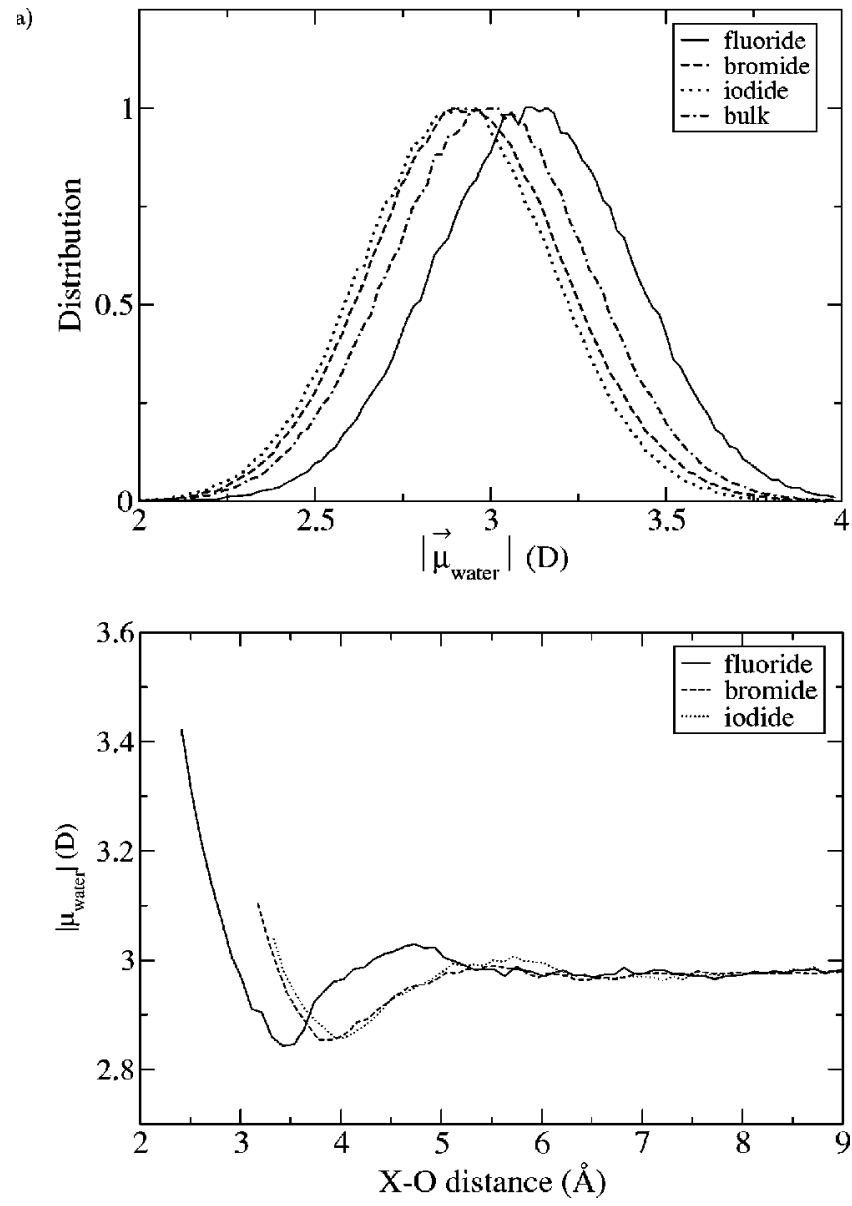

FIG. 7. (a) Distribution of the water dipole moment in the first hydration shell along with the module of the dipole moment of pure water. (b) Average per-molecule dipole moment of water as a function of the $X-\mathrm{O}$ distance.

model used by Tuñon et al. ${ }^{77}$ This fact may be responsible for a more symmetric hydration structure around the anion. Bearing this idea in mind, the estimated value of the halide dipole moment can be used as a measurement of the symmetry of the first solvation shell. In this sense, the sequence $\left|\vec{\mu}_{\mathrm{F}_{\text {ind }}^{-}}\right|<\left|\vec{\mu}_{\mathrm{Br}_{\text {ind }}^{-}}\right|<\left|\vec{\mu}_{\mathrm{I}_{\text {ind }}^{-}}\right|$can also be interpreted in terms of an increasing of the asymmetry of the water molecules around the halide ion.

The experimental polarizability volume of the halide ion $^{78}$ increases from the fluoride ion $\left(0.87 \AA^{3}\right)$ to the bromide ion $\left(4.85 \AA^{3}\right)$ and to the iodide ion $\left(7.50 \AA^{3}\right)$. The MCDHO model allows the calculation of this magnitude. The results are $0.97,4.0$ and $5.8 \AA^{3}$ for the $\mathrm{F}^{-}, \mathrm{Br}^{-}$and $\mathrm{I}^{-}$, respectively. It is worth mentioning that ion model parameters were not chosen in such a way that the halide polarizability fitted the experimental value, nevertheless, they are able to reproduce the experimental trend. This situation is similar to the one found by Ortega-Blake et al. ${ }^{14}$ for the water molecule where the MCDHO polarizability is $1.35 \AA^{3}$ and the experimental one is $1.42-1.47 \AA^{3}$.

\section{CONCLUDING REMARKS}

The results derived from the MCDHO-type halide ionwater interaction potentials show a fairly good agreement regarding the theoretical and experimental data for both clus- ters and condensed matter studies. This fact shows how intermolecular interaction potentials based on first principles give the basic and common ingredients to describe halide containing systems both in gas phase and solution.

The analysis of the arrangement of water molecules around the halide ions indicates that there is a compromise between the energetic competition of halide-water and waterwater interactions and the polarizable-polarizing character of the halide ion.

The distortion of water molecules have only slightly noticeable effects on the $\mathrm{O}-\mathrm{H}$ distance, especially in the case of the fluoride ion.

The dipole moment of the water molecules in the first hydration shell is affected by the anion presence and it is necessary to consider its change to understand the microsolvation of the fluoride ion. The developed potentials supply a continuous way to deal with clusters in gas phase and halide ions in water, a priori all interactions are treated on the same footing. The physics of the problem being the discriminating factor between both types of situations (vacuum versus condensed medium).

The analysis of the distribution of $\phi$ and $\gamma$ angles in the first hydration shell of the halide anions indicates an increasing dispersion of these values from $\mathrm{F}^{-}$to $\mathrm{I}^{-}$. This sequence combined with the analysis of the RDF $X-\mathrm{O}$ and $X-\mathrm{H}$ illustrates the fact that water molecule reorientation around the halide anion is progressively lost when increasing the atomic number of the halide.

\section{ACKNOWLEDGMENTS}

Spanish DGICYT (BQU2002-02217) is acknowledged for financial support. R.A.E. thanks the Spanish MECD for a FPU fellowship.

${ }^{1}$ H. Ohtaki and T. Radnai, Chem. Rev. 93, 1157 (1993).

${ }^{2}$ Y. Marcus, Ion Solvation (Wiley, Chichester, 1986).

${ }^{3}$ Y. Marcus, Ion Properties (Marcel Dekker, New York, 1997).

${ }^{4}$ B. E. Conway, Ionic Hydration in Chemistry and Biophysics. Studies in Physical and Theoretical Chemistry (Elsevier, Amsterdam, 1981), Vol. 12.

${ }^{5}$ B. Y. Simkin and I. I. Sheikhet, Quantum Chemical and Statistical Theory of Solutions: A Computational Approach (Ellis Horwood, London, 1995).

${ }^{6}$ S. K. Searles and P. Kebarle, Can. J. Chem. 47, 2619 (1969).

${ }^{7}$ M. Arshadi, R. Yamdagni, and P. Kebarle, J. Phys. Chem. 74, 1475 (1970).

${ }^{8}$ R. G. Keesee and A. Castleman, Jr., Chem. Phys. Lett. 74, 139 (1980).

${ }^{9}$ D. T. Richens, The Chemistry of Aqua Ions (Wiley, Chichester, 1997).

${ }^{10}$ M. P. Allen and D. J. Tildesley, Computer Simulation of Liquids (Oxford University Press, Oxford, 1987).

${ }^{11}$ D. W. Hermann, Computer Simulation Methods (Springer-Verlag, Berlin, 1990).

${ }^{12}$ F. Floris and A. Tani, in Molecular Dynamics: From Classical to Quantum Methods, edited by P. B. Balbuena and J. M. Seminario (Elsevier, Amsterdam, 1999), Vol. 7, Chap. 10.

${ }^{13}$ A. J. Stone, The Theory of Intermolecular Forces (Clarendon, Oxford, 1996).

${ }^{14}$ H. Saint-Martin, J. Hernandez-Cobos, M. I. Bernal-Uruchurtu, I. OrtegaBlake, and H. J. C. Berendsen, J. Chem. Phys. 113, 10899 (2000).

${ }^{15}$ R. Ayala, J. M. Martínez, R. R. Pappalardo, H. Saint-Martin, I. OrtegaBlake, and E. Sánchez Marcos, J. Chem. Phys. 117, 10512 (2002).

${ }^{16}$ R. Ayala, J. M. Martínez, R. R. Pappalardo, and E. Sánchez Marcos, J. Phys. Chem. A 104, 2799 (2000).

${ }^{17}$ L. X. Dang, J. E. Rice, J. Caldwell, and P. A. Kollman, J. Am. Chem. Soc. 113, 2481 (1991).

${ }^{18}$ L. X. Dang, J. Chem. Phys. 96, 6970 (1992).

${ }^{19}$ P. J. Merkling, R. Ayala, J. M. Martínez, R. R. Pappalardo, and E. Sánchez Marcos, J. Chem. Phys. 119, 6647 (2003). 
${ }^{20}$ L. Perera and M. L. Berkowitz, J. Chem. Phys. 95, 1954 (1991).

${ }^{21}$ L. S. Sremaniak, L. Perera, and M. L. Berkowitz, Chem. Phys. Lett. 218, 377 (1994).

${ }^{22}$ J. E. Combariza, N. R. Kestner, and J. Jortner, Chem. Phys. Lett. 203, 423 (1993).

${ }^{23}$ J. E. Combariza, N. R. Kestner, and J. Jortner, J. Chem. Phys. 100, 2851 (1994).

${ }^{24}$ J. E. Combariza, N. R. Kestner, and J. Jortner, Chem. Phys. Lett. 221, 156 (1994).

${ }^{25}$ R. A. Bryce, M. A. Vincent, and I. H. Hillier, J. Phys. Chem. A 103, 4094 (1999).

${ }^{26}$ W. H. Robertson and M. A. Johnson, Annu. Rev. Phys. Chem. 54, 173 (2003).

${ }^{27}$ J. Baik, J. Kim, D. Majumdar, and K. S. Kim, J. Chem. Phys. 110, 9116 (1999).

${ }^{28}$ J. Kim, H. M. Lee, S. S. Suh, and K. S. Kim, J. Chem. Phys. 113, 5259 (2000).

${ }^{29}$ O. M. Cabarcos, C. J. Weinheimer, J. M. Lisy, and S. S. Xantheas, J. Chem. Phys. 110, 5 (1999).

${ }^{30}$ J. E. Combariza and N. R. Kestner, J. Phys. Chem. 98, 3513 (1994).

${ }^{31}$ J. D. C. Craig and M. H. Brooker, J. Solution Chem. 29, 879 (2000).

${ }^{32}$ I. A. Topol, G. J. Tawa, S. K. Burt, and A. A. Rashin, J. Chem. Phys. 111, 10998 (1999).

${ }^{33}$ S. S. Xantheas and T. H. Dunning, Jr., J. Phys. Chem. 98, 13489 (1994).

${ }^{34}$ J. Gao, D. S. Gainer, and W. L. Jorgensen, J. Am. Chem. Soc. 108, 4784 (1986).

${ }^{35}$ A. M. Kuznetsov, Chem. Phys. 179, 47 (1994).

${ }^{36}$ H. M. Lee, D. Kim, and K. S. Kim, J. Chem. Phys. 116, 5509 (2002).

${ }^{37}$ G. M. Chaban, S. S. Xantheas, and R. B. Gerber, J. Phys. Chem. A 107, 4952 (2003).

${ }^{38}$ R. A. Bryce, M. A. Vincent, N. O. J. Malcolm, and I. H. Hillier, J. Chem. Phys. 109, 3077 (1998).

${ }^{39}$ S. Koneshan, J. C. Rasaiah, and L. X. Dang, J. Chem. Phys. 114, 7544 (2001).

${ }^{40}$ S. S. Xantheas and L. X. Dang, J. Phys. Chem. 100, 3989 (1996).

${ }^{41}$ L. S. Sremaniak, L. Perera, and M. L. Berkowitz, J. Phys. Chem. 100, 1350 (1996)

${ }^{42}$ L. Perera and M. L. Berkowitz, J. Chem. Phys. 100, 3085 (1994).

${ }^{43}$ S. Koneshan, J. Rasaiah, M. Lynden-Bell, and H. Lee, J. Phys. Chem. B 102, 4193 (1998).

${ }^{44}$ H. Lee and J. Rasaiah, J. Phys. Chem. 100, 1420 (1996).

${ }^{45}$ S. J. Vaughn, E. V. Akhmastkaya, M. A. Vincent, A. J. Masters, and I. H. Hillier, J. Chem. Phys. 110, 4338 (1999).

${ }^{46}$ H. M. Lee and K. S. Kim, J. Chem. Phys. 114, 4461 (2001)

${ }^{47}$ J. E. Combariza, N. R. Kestner, and J. Jortner, Chem. Phys. Lett. 221, 156 (1994).

${ }^{48}$ S. E. Bradforth and P. Jungwirth, J. Phys. Chem. A 106, 1286 (2002).
${ }^{49}$ F. D. Vila and K. D. Jordan, J. Phys. Chem. A 106, 1391 (2002).

${ }^{50}$ H. S. Chen and W. S. Shen, J. Am. Chem. Soc. 122, 7534 (2002).

${ }^{51}$ H. Gai, G. K. Schenter, L. X. Dang, and B. C. Garret, J. Chem. Phys. 105, 8835 (1996).

${ }^{52}$ L. X. Dang and B. C. Garret, J. Chem. Phys. 99, 2972 (1993).

${ }^{53}$ L. X. Dang, J. Chem. Phys. 110, 1526 (1999).

${ }^{54}$ R. M. Linden-Bell and J. C. Rasaiah, J. Chem. Phys. 107, 1981 (1997).

${ }^{55}$ G. H. Peslherbe, B. M. Ladanyi, and J. T. Hynes, J. Phys. Chem. A 104, 4533 (2000).

${ }^{56}$ A. D. E. Woon and T. H. Dunning, Jr., J. Chem. Phys. 98, 1358 (1993).

${ }^{57}$ R. A. Kendall, T. H. Dunning, and R. J. Harrison, J. Chem. Phys. 96, 6796 (1992).

${ }^{58}$ E. R. Davidson, Chem. Phys. Lett. 260, 51 (1996).

${ }^{59}$ T. H. Dunning, J. Chem. Phys. 90, 1007 (1989).

${ }^{60}$ S. S. Xantheas, J. Phys. Chem. 100, 9703 (1996).

${ }^{61}$ S. S. Xantheas and T. H. Dunning, Jr., J. Chem. Phys. 98, 8037 (1993).

${ }^{62}$ S. S. Xantheas and T. H. Dunning, Jr., J. Chem. Phys. 99, 8774 (1993).

${ }^{63}$ A. Begner, M. Dolg, W. Kÿchle, H. Stoll, and H. Preuss, Mol. Phys. 80, 1431 (1993).

${ }^{64}$ J. M. L. Martin and A. Sundermann, J. Chem. Phys. 114, 3408 (2001).

${ }^{65}$ O. Mó, M. Yáñez, and J. Elguero, J. Chem. Phys. 97, 6628 (1992).

${ }^{66}$ O. Mó, M. Yáñez, I. Rozas, and J. Elguero, J. Chem. Phys. 100, 2871 (1994)

${ }^{67}$ S. F. Boys and F. Bernardi, Mol. Phys. 19, 553 (1970).

${ }^{68}$ M. J. Frisch, G. W. Trucks, H. B. Schlegel et al., GAUSSIAN 98, Gaussian, Inc., Pittsburgh, PA, 1998

${ }^{69}$ MCHANG program. This library is available upon request at jorge @ fis.unam.mx.

${ }^{70}$ M. Masamura, J. Phys. Chem. A 106, 8925 (2002).

${ }^{71}$ M. Masamura, J. Chem. Phys. 118, 6336 (2003).

${ }^{72}$ J. E. Roberts and J. Schnitker, J. Phys. Chem. 99, 1322 (1995).

${ }^{73}$ M. Leslie and M. J. Gillan, J. Phys.: Condens. Matter 18, 973 (1985).

${ }^{74}$ J.-H. Choi, K. T. Kuwata, Y.-B. Cao, and M. Okumura, J. Phys. Chem. A 102, 503 (1998)

${ }^{75}$ The deformation energy for the water molecule in the case of the $\left[\mathrm{Li}\left(\mathrm{H}_{2} \mathrm{O}\right)\right]^{+}$cluster was computed using the $6-311++\mathrm{g} * *$ basis set. The deformation energy for the water molecule in the $\left[\mathrm{F}\left(\mathrm{H}_{2} \mathrm{O}\right)\right]^{-}$cluster at the same computational level was $4.7 \mathrm{kcal} / \mathrm{mol}$.

${ }^{76}$ S. Raugei and M. L. Klein, J. Chem. Phys. 116, 196 (2002).

${ }^{77}$ I. Tuñón, M. T. C. Martins-Costa, C. Millot, and M. F. Ruíz-López, Chem. Phys. Lett. 241, 450 (1995).

${ }^{78}$ L. Pauling, Proc. R. Soc. London, Ser. A 114, 191 (1927).

${ }^{79}$ K. Hiraoka, S. Mizuse, and S. Yamabe, J. Phys. Chem. 92, 3943 (1988).

${ }^{80}$ G. I. Szasz, K. Heinzinger, and W. O. Riede, Z. Naturforsch. A 36A, 1067 (1981). 